\title{
Diazepam or midazolam for orotracheal intubation in the ICU?
}

\author{
Lísia Gehrke ${ }^{1}$, Roselaine P. Oliveira ${ }^{2}$, Maicon Becker ${ }^{3}$, Gilberto Friedman ${ }^{4}$ \\ ${ }^{1}$ Medical intensivist, Dr. Bartholomeu Tocchini Hospital, Intensive Care Unit, Bento Gonçalves, RS, Brazil \\ ${ }^{2}$ Adjunct professor, Department of Clinical Medicine, Federal University of Health Sciences of Porto Alegre (UFCSPA), Porto Alegre, RS, Brazil \\ ${ }^{3}$ Medical intensivist, Pompéia Hospital, Intensive Care Unit, Caxias do Sul, RS, Brazil \\ ${ }^{4}$ Associate professor, Department of Internal Medicine, Faculty of Medicine, Federal University of Rio Grande do Sul (UFRGS), Porto Alegre, RS, Brazil
}

Study conducted at the Intensive Care Unit of the Santa Casa Hospital Complex in Porto Alegre, Brazil

Article received: $4 / 6 / 2014$ Accepted for publication: $6 / 3 / 2014$

*Correspondence: Address: Rua Fernandes Vieira, 181/601 Postal Code: $90035-091$ Porto Alegre - RS - Brazil beto_gremio@hotmail.com

http://dx.doi.org/10.1590/1806-9282.61.01.030 Conflict of interest: none

\section{SUMmARY}

Objective: to compare clinical and cost effectiveness of midazolam and diazepam for urgent intubation.

Methods: patients admitted to the Central ICU of the Santa Casa Hospital Complex in Porto Alegre, over the age of 18 years, undergoing urgent intubation during 6 months were eligible. Patients were randomized in a single-blinded manner to either intravenous diazepam or midazolam. Diazepam was given as a $5 \mathrm{mg}$ intravenous bolus followed by aliquots of $5 \mathrm{mg}$ each minute. Midazolam was given as an intravenous bolus of $5 \mathrm{mg}$ with further aliquots of $2.5 \mathrm{mg}$ each minute. Ramsay sedation scale 5-6 was considered adequate sedation. We recorded time and required doses to reach adequate sedation and duration of sedation.

Results: thirty four patients were randomized, but one patient in the diazepam group was excluded because data were lost. Both groups were similar in terms of illness severity and demographics. Time for adequate sedation was shorter $(132 \pm 87$ $\sec v$ s. $224 \pm 117 \mathrm{sec}, \mathrm{p}=0.016)$ but duration of sedation was similar $(86 \pm 67 \mathrm{~min} v \mathrm{~s}$ $88 \pm 50 \mathrm{~min}, \mathrm{p}=0.936$ ) for diazepam in comparison to midazolam. Total drug dose to reach adequate sedation after either drugs was similar (10.0 [10.0-12.5] mg vs. 15.0 [10.0-17.5] $\mathrm{mg}, \mathrm{p}=0.248$ ). Arterial pressure and sedation intensity reduced similarly overtime with both drugs. Cost of sedation was lower for diazepam than for midazolam (1.4[1.4-1.8] vs. 13.9[9.4-16.2] reais, $\mathrm{p}<0.001)$.

Conclusions: intubation using intravenous diazepam and midazolam is effective and well tolerated. Sedation with diazepam is associated to a quicker sedation time and to lower costs.

Keywords: deep sedation, drug costs, intubation, randomized controlled trial, diazepam, midazolam.

\section{INTRODUCTION}

When physicians around the world started using diazepam in the 1960s, numerous studies were published showing that intravenous diazepam as sole sedative agent was safe, easy to use and well tolerated by patients. ${ }^{1-4}$ In the late 1970s and 1980s, midazolam replaced diazepam as first choice sedative for several procedures basically due to its better amnesia properties. ${ }^{5-14}$ It has repeatedly been shown that physician-led sedation using the benzodiazepine diazepam is also safe and has a positive impact on patient acceptability of the procedure. ${ }^{15,16}$

In several countries, benzodiazepines are still the main drug of choice for procedures instead of using newer, rapidly acting, anesthetics, largely driven by cost concerns. ${ }^{16}$
In the Santa Casa Hospital Complex (seven hospitals and eight ICUs), midazolam is the drug most used - and frequently solely used - for sedation in procedures like upper endoscopy, cardioversion or intubation.

The sedation time is reduced with midazolam compared with diazepam in several studies on medical procedures but the differences are not clinically relevant. ${ }^{6,16,17}$ The awakening time is considerably longer for midazolam so that any time gained with induction of sedation is lost in the longer recovery. ${ }^{15,16,18-20}$ However, most patients that need urgent intubation in the ICU will need continuous sedation, mainly due to respiratory insufficiency.

Studies examining the effects of midazolam reveal that they are similar to those of diazepam with few he- 
modynamic alterations. ${ }^{16,17,21,22}$ Hypotension is observed with both diazepam and midazolam. This side effect can be of relevance when inducing sedation in a patient already hemodinamically unstable as several patients in need of urgent intubation.

There are no randomized trials comparing midazolam and diazepam for sedation in urgent oral-tracheal intubation. The finding of clinical equivalence between the two drugs in quality of sedation and adverse effects would allow institutions to choose between the agents on a drug cost basis. Eight years ago we performed a randomized study to compare both drugs during hospital financial crisis and a partial analysis of results was presented in an international congress. ${ }^{23}$ We are motivated to publish the results because the issue is up to date for several institutions in our country and others. Firstly, we hypothesized that diazepam and midazolam produce equal quality of sedation and, secondly, hemodynamic instability is equally significantly with both drugs. The main aim of this study was to compare the clinical effectiveness and after-effects of midazolam and diazepam in a single-blinded randomized design, during emergency intubation in the ICU. Also, we aimed to compare drug costs for adequate sedation during the procedure.

\section{Methods}

The local research ethical committee approved the study. The need for an informed consent was waived by the ethics committee as both drugs are commercially available and used by intensivists for the study procedure in the last thirty years. All patients admitted to the Central Intensive Care Unit of the Santa Casa Hospital Complex in Porto Alegre, over the age of 18 years, undergoing the first urgent intubation during ICU stay between May 2005 and October 2005 were eligible for the study. Patients were excluded if they had allergy to either drug, or if they were already under sedation. Immediately after decision to intubate, once all inclusion and exclusion criteria were met, patients were randomized in a single-blinded manner (opaque sealed envelopes) to either diazepam or midazolam for intravenous sedation during the procedure. Patients or families were not told which type of sedation they received but operators were unblinded.

All intubations were coordinated by a senior intensivist of the staff. Pre-intubation protocol followed our standard procedures for preparation (i.e. positioning, oxymeter, monitor) and preoxygenation before medication. The attending doctor administered the sedative according to a titration protocol. Diazepam was given as a $5 \mathrm{mg}$ intravenous bolus followed by aliquots of $5 \mathrm{mg}$ each minute. Midazolam was given as an intravenous bolus of $5 \mathrm{mg}$ with further aliquots of $2.5 \mathrm{mg}$ each minute. The use of an opioid (morphine or fentanyl) or neuromuscular blockers was allowed at discretion of the attending doctor. ECG, oxygen saturation, respiratory rate, and blood pressure monitoring were performed continuously throughout the procedure. Adequate sedation was considered whenever a Ramsay sedation scale 5-6 was reached.

Sedation time was recorded as the time from first injection to the time of adequate sedation. Oral-tracheal intubation was performed according to the standard ICU procedure. Each patient was observed during $60 \mathrm{~min}$ since first injection, every 15 minutes and thereafter continuously received sedation and analgesia to facilitate mechanical ventilation. During the observation period, we evaluated required doses of each drug, time to adequate sedation and duration of sedation. The following demographic variables were collected for all patients: age, gender, admission diagnosis, Acute Physiology and Chronic Health Evaluation II severity score (Apache II). ${ }^{24}$

\section{Statistics}

Data are presented as mean \pm standard deviation or median (25-75 percentiles) according to the statistical test used. Comparisons of non-parametric data were by Mann-Whitney U tests. Parametric data were compared with unpaired Student's t tests. Cardiovascular and oxygenation parameters at each time were analyzed with a two-way repeated measures analysis of variance with post hoc Dunnett's test (within groups) and single degree of freedom tests (between groups) when significance was detected. Nominal data were analyzed by Chi-square or Fisher's exact test, as appropriate. $\mathrm{P}<0.05$ was considered significant. Calculation of sample size indicated 17 patients in each group with a power of 0.8 and alpha 0.05 , based on a pilot study after inclusion of 5 patients in each group and using a 30\% difference on time for adequate sedation as outcome.

\section{Results}

Between May 2005 and October 2005, 76 patients were intubated in the Central Intensive Care Unit. Twenty five patients were excluded from the study because they were under sedatives prior to intubation. Twenty patients were excluded because the assistant intensivist decided to use another sedative (e.g. propofol) or the intubation was considered urgent and no randomization was performed. Thirty four patients were randomized, but one patient in the diazepam group was excluded from the analysis because all data were lost. Patients' characteristics are shown in Table 1. Both groups were similar in terms of illness severity and demographic data. 


\section{TABLE 1 Characteristics of patients}

\begin{tabular}{l|l|l|l} 
Parameters & $\begin{array}{l}\text { Midazolam } \\
(\mathbf{n = 1 7})\end{array}$ & $\begin{array}{l}\text { Diazepam } \\
(\mathbf{n = 1 6 )}\end{array}$ & $\mathbf{P}$ value \\
\hline Age (years) & $62 \pm 13$ & $60 \pm 18$ & 0.698 \\
\hline Apache II & $23 \pm 7$ & $25 \pm 10$ & 0.633 \\
\hline Sex (male/female) & $9 / 8$ & $8 / 8$ & 1.000 \\
\hline Glasgow coma scale & $13 \pm 4$ & $12 \pm 3$ & 0.462 \\
\hline Weight $(\mathrm{kg})$ & $67 \pm 18$ & $65 \pm 13$ & 0.611 \\
\hline Height $(\mathrm{cm})$ & $164 \pm 8$ & $166 \pm 8$ & 0.454 \\
\hline BMI & $25 \pm 6$ & $23 \pm 3$ & 0.431 \\
\hline
\end{tabular}

Causes of intubation

\begin{tabular}{l|l|l|l}
\hline Hypoxemia & 8 & 8 & 1.000 \\
\hline Hypercapnia & 4 & 3 & 1.000 \\
\hline Mixed respiratory failure & 2 & 4 & 0.398 \\
\hline Coma & 3 & 1 & 0.601 \\
\hline
\end{tabular}

Diagnosis on study admission

\begin{tabular}{l|l|l|l}
\hline Renal failure & 2 & 3 & 0.656 \\
\hline Diabetes & 1 & 4 & 0.175 \\
\hline Ischemic heart disease & 0 & 1 & 0.485 \\
\hline Arterial hypertension & 6 & 7 & 0.728 \\
\hline Ischemic stroke & 5 & 3 & 0.688 \\
\hline
\end{tabular}

Acute Physiology and Chronic Health Evaluation (Apache) II score; Body mass index.

Time for adequate sedation (Figure 1) was shorter but duration of sedation was similar for diazepam in comparison to midazolam (Figure 2). Total drug dose to reach adequate sedation after intravenous diazepam or midazolam was not different (10.0 [10.0-12.5] mg vs. 15.0 [10.0$17.5] \mathrm{mg}, \mathrm{p}=0.248$ ). There were no differences between study drugs during time for cardiorespiratory parameters or sedation intensity (Table 2). Arterial pressure and
Ramsay scale reduced significantly after 15 minutes for both drugs. The proportion of patients that experienced hypotension (Systolic pressure $<90 \mathrm{mmHg}$ ) was similar for midazolam and diazepam (10 patients $v$ s. 10 patients). Four patients received a bolus of fentanyl in the midazolam and diazepam groups $(130 \pm 26 \mu \mathrm{g} v \mathrm{~s} .125 \pm 19 \mu \mathrm{g}, \mathrm{p}=$ $0.76)$. One patient received a $5 \mathrm{mg}$ bolus of morphine in the midazolam group. None of the patients was intubated under paralysis.

Single use ampoules were used and excess drug was discarded between cases. The current (January-2014) cost of sedation (syringes and ampoules) with diazepam, 1.40 [1.40-1.85] reais, was significantly lower than with midazolam, 13.90 [9.40-16.25] reais, $\mathrm{p}<0.001$.

Senior intensivists were not required in any of the intubations.

\section{Discussion}

This study showed that both midazolam and diazepam were safe and well tolerated for physician-led sedation during urgent oral-tracheal intubation. At the doses used, they were equally effective and without major adverse events following the procedure.

Important differences between the clinical effects of the studied drugs when used in this manner were identified. Surprisingly, the sedation time was significantly reduced with diazepam compared with midazolam. In comparative studies with diazepam in several procedures, midazolam proved more effective at inducing rapid sedation. ${ }^{16,18-20} \mathrm{Mi}-$ dazolam is known to be rapidly absorbed and the onset of action is, therefore, faster than that of diazepam and its effects are expected to occur sooner than those of diazepam.

\begin{tabular}{|c|c|c|c|c|c|c|}
\hline & & Basal & Bolus & $15 \mathrm{~min}$ & $30 \mathrm{~min}$ & $60 \mathrm{~min}$ \\
\hline \multirow[t]{2}{*}{ Heart rate (beats/min) } & Midazolam & $105 \pm 16$ & $103 \pm 15$ & $103 \pm 16$ & $99 \pm 15$ & $99 \pm 14$ \\
\hline & Diazepam & $107 \pm 25$ & $108 \pm 28$ & $105 \pm 31$ & $99 \pm 26$ & $98 \pm 23$ \\
\hline \multirow[t]{2}{*}{ Systolic pressure (mmHg) } & Midazolam & $127 \pm 31$ & $107 \pm 37$ & $93 \pm 23^{*}$ & $93 \pm 20^{*}$ & $110 \pm 30$ \\
\hline & Diazepam & $129 \pm 39$ & $116 \pm 42$ & $107 \pm 37^{*}$ & $97 \pm 33^{*}$ & $112 \pm 35$ \\
\hline \multirow{2}{*}{ Diastolic pressure $(\mathrm{mmHg})$} & Midazolam & $67 \pm 14$ & $58 \pm 156$ & $58 \pm 20$ & $55 \pm 13^{*}$ & $63 \pm 18$ \\
\hline & Diazepam & $70 \pm 20$ & $64 \pm 20$ & $57 \pm 20$ & $56 \pm 21^{*}$ & $60 \pm 19$ \\
\hline \multirow[t]{2}{*}{ Respiratory rate (breaths/min) } & Midazolam & $29 \pm 11$ & $27 \pm 7$ & $21 \pm 4^{*}$ & $20 \pm 3^{*}$ & $22 \pm 3^{*}$ \\
\hline & Diazepam & $27 \pm 9$ & $25 \pm 8$ & $22 \pm 6^{*}$ & $22 \pm 3^{*}$ & $22 \pm 4^{*}$ \\
\hline \multirow[t]{2}{*}{ Arterial oxygen saturation (\%) } & Midazolam & $91 \pm 5$ & $92 \pm 5$ & $96 \pm 2$ & $95 \pm 3$ & $95 \pm 4$ \\
\hline & Diazepam & $89 \pm 16$ & $86 \pm 19$ & $90 \pm 16$ & $90 \pm 20$ & $95 \pm 6$ \\
\hline \multirow[t]{2}{*}{ Ramsay scale } & Midazolam & $1.0[1.0-2.0]$ & $2.0[1.0-5.5]$ & $5.0[4.5-6.0]^{*}$ & $5.0[4.5-6.0]^{*}$ & $5.0[4.0-5.5]^{*}$ \\
\hline & Diazepam & $2.0[1.0-2.5]$ & $2.0[1.0-5.0]$ & $6.0[5.0-6.0]^{*}$ & $5.0[5.0-6.0]^{*}$ & $5.0[4.0-5.7]^{*}$ \\
\hline
\end{tabular}

${ }^{*} p<0.05$ vs. baseline. No significance differences were observed between groups for each time. 


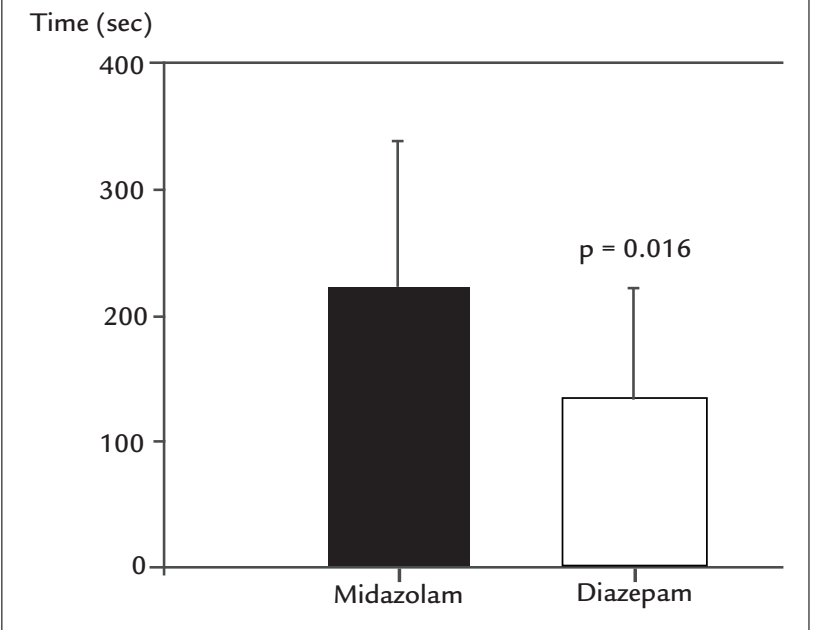

FIGURE 1 Time for adequate sedation (Ramsay sedation scale 5-6) was shorter after intravenous diazepam $(n=16)$ in comparison to midazolam $(n=17)$.

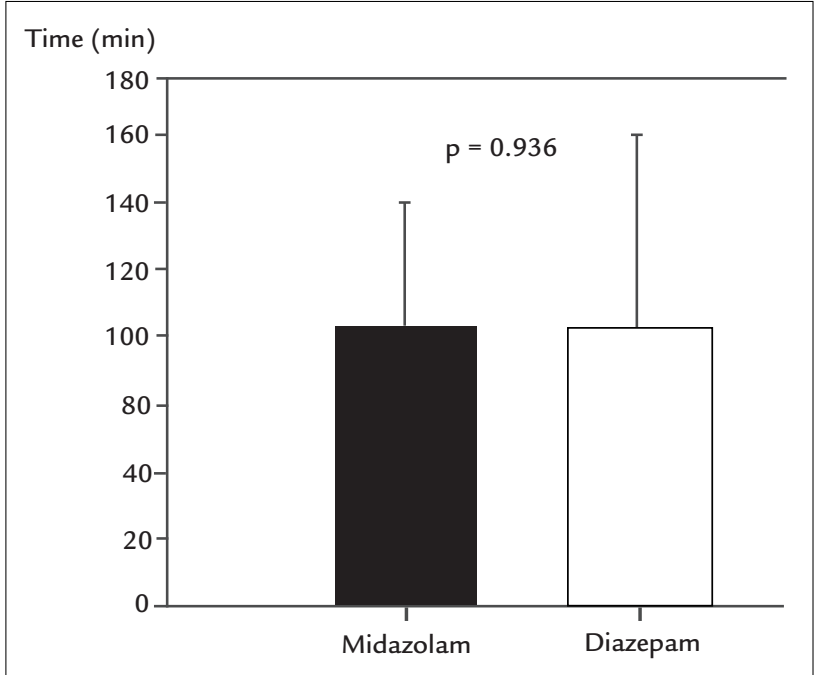

FIGURE 2 Duration of sedation (min) until Ramsay scale $<5$ after intravenous midazolam $(n=17)$ or diazepam $(n=16)$ was similar.

In addition, the dose of both drugs to reach adequate sedation was similar. This finding is in contrast to several studies that have shown than midazolam is 2-3 times more potent than diazepam. ${ }^{16,17}$ We speculated that although this finding looks contradictory, a wide individual variation in dose-effect response was seen, as shown by the range of total dosages required in this study. These wide variations in response are typical of benzodiazepines and may be partly explained by high plasma protein binding. ${ }^{25,26}$ Obese patients have an increased volume of distribution due to enhanced distribution in peripheral adipose tissues and interactions with other drugs that are metabolized through the cytochrome 450 system can influence the clinical response. ${ }^{27}$ Benzodiazepines have synergistic interactions with other drugs like opioids that were simultaneously used in most patients. Pharmacokinetics of almost all drugs, including sedatives, are not well known in critically ill patients. ${ }^{28,29}$

The reduction in blood pressure and the incidence of hypotension observed with midazolam and diazepam (60\% of patients) may have been related to the high doses used to achieve rapid sedation in already sick patients prone to hemodynamic instability. Fifteen episodes of hypotension in this study occurred within the first $15 \mathrm{mi}-$ nutes. It has been shown that the use of both diazepam and midazolam is associated with decreased systolic blood pressure. ${ }^{30}$ Midazolam is particularly associated with reduction in both systemic vascular resistance and diastolic pressure. ${ }^{30}$

The lower cost with diazepam is an important finding. Although both drugs have generic presentations with lowering costs in the last decade, diazepam costs were much lower both because one milligram of diazepam is cheaper than one milligram of midazolam and the concentration used for the same sedative effect was smaller. Although cost evaluation was not precise because we did not include expenses with diluents, for instance, drug cost itself accounts for the greater part of it. The cost of one syringe was 0.4 real and for most cases a single one was needed.

The study has several limitations. The study was single-blinded and operator observations may have been influenced by individual experience and preference with each form of sedation. Due to the different titration properties and appearance of the two drugs, blinding the drug to the operator was not ideal. No adjustments were made in this study for body weight or concomitant drug use. We used the end-point of Ramsay scale 5-6 to indicate an adequate level of sedation. Despite the scale of Ramsay being mostly used these days, there is good correlation with other scales, particularly the Richmond Agitation-Sedation scale, and our end point was deep sedation which has excellent equivalence in most scales. ${ }^{31} \mathrm{In}$ addition, both groups included patients with somewhat low Glasgow coma scale or previous strokes that could interfered the sedation evaluation. The study is 8 years old and medical practices may have changed. For instance, the use of rapid sequence intubation as a standard protocol is not yet well incorporated by most physicians, both in our ICU and emergency room. However, the use of midazolam is still the most current practice for hundreds of procedures performed in more than $110 \mathrm{ICU}$ adult beds in our Hospital Complex. 
Physician-led intubation using intravenous diazepam and midazolam is highly effective and well tolerated, with only minor effects. Sedation with diazepam is associated to a quicker sedation time than midazolam and to lower costs.

\section{Resumo}

Diazepam ou midazolam para entubação orotraqueal na UTI?

Objetivo: comparar eficácia clínica e custo de midazolam e diazepam para intubação urgente.

Métodos: pacientes internados na UTI Central do Complexo Hospitalar Santa Casa de Porto Alegre, >18 anos de idade e submetidos a entubação urgente durante seis meses eram elegíveis. Pacientes foram randomizados para receber diazepam ou midazolam intravenoso. Diazepam foi dado como bolus IV de $5 \mathrm{mg}$ seguido por alíquotas de 5 $\mathrm{mg}$ a cada minuto. Midazolam foi dado como um bolus IV de $5 \mathrm{mg}$, com alíquotas adicionais de $2,5 \mathrm{mg}$ a cada minuto. Escala de sedação de Ramsay 5-6 foi considerada sedação adequada. Registramos tempo e doses necessárias para atingir sedação adequada e sua duração.

Resultados: trinta e quatro pacientes foram randomizados; um paciente no grupo diazepam foi excluído por perda dos dados. Grupos foram semelhantes para gravidade da doença e demografia. Tempo de sedação adequada foi mais curto (132 \pm 87 vs. $224 \pm 117$ segundos, $\mathrm{p}=0,016)$, mas a duração da sedação foi similar $(86 \pm 67$ vs. $88 \pm 50$ min., $p=0,936)$ para o diazepam em comparação com o midazolam. Dose total da droga para atingir a sedação adequada foi semelhante para ambas as drogas $(10,0[10,0-12,5]$ vs. $15,0[10,0-17,5]$ $\mathrm{mg}, \mathrm{p}=0,248)$. Pressão arterial e intensidade da sedação reduziram da mesma forma para ambas as drogas ao longo do tempo. O custo da sedação foi menor para diazepam do que para midazolam $(1,4[1,4-1,8]$ vs. 13,9[9,4-16,2] reais, $\mathrm{p}<0,001)$. Conclusões: entubação usando diazepam e midazolam intravenosos é eficaz e bem tolerada. Sedação com diazepam está associada a sedação mais rápida e menores custos.

Palavras-chave: sedação profunda, entubação, diazepam, midazolam, ensaio clínico controlado aleatório, custos de medicamentos.

\section{References}

1. Kahler RL, Burrow GN, Felig P. Diazepam-induced amnesia for cardioversion. JAMA $1967 ;$ 200:997-998.

2. Nutter DO, Massumi RA. Diazepam in cardioversion. N Engl J Med 1965; 273(12):650-651.

3. Lebowitz WB. Electrical conversion of arrhythmias under diazepam sedation. Conn Med 1969; 33:173-174.

4. Naney AP, Chaffee WG. Diazepam for cardioversion. JAMA 1971; 215:487.

5. Al Khudhairi D, Whitwam JG, McCloy RF. Midazolam and diazepam for gastroscopy. Anaesthesia 1982; 37:1002-1006
6. Whitwam JG, Al Khudhairi D, McCloy RF. Comparison of midazolam and diazepam in doses of comparable potency during gastroscopy. Br J Anaesth 1983; 55:773-777.

7. Brouillette DE, Leventhal R, Kumar S, Berman D, Kajani M, Yoo YK et al. Midazolam versus diazepam for combined esophogastroduodenoscopy and colonoscopy. Dig Dis Sci 1989; 34:1265-1271.

8. Krichbaum DW, Hamid I. Midazolam sedation and amnesia in elective cardioversion. Clin Pharm 1988; 7:423.

9. Gupta A, Lennmarken C, Vegfors M, Tyden H. Anaesthesia for cardioversion. A comparison between propofol, thiopentone and midazolam. Anaesthesia $1990 ; 45: 872-875$.

10. Gupta A, Vegfors M, Lennmarken C. Midazolam and cardioversion. Br J Anaesth 1992; 69:422.

11. Dickinson ET, Cohen JE, Mechem CC. The effectiveness of midazolam as a single pharmacologic agent to facilitate endotracheal intubation by paramedics. Prehosp Emerg Care 1999; 3:191-193.

12. Schwander D, Sansano C. Cardiovascular changes during intubation with midazolam as anaesthesia inducing agent. Arzneimittelforschung 1981; 31:2255-2260.

13. Boralessa H, Senior DF, Whitwam JG. Cardiovascular response to intubation. A comparative study of thiopentone and midazolam. Anaesthesia 1983; 38:623-627.

14. Sabbatani P, Mantovan R. Electrical cardioversion of atrial fibrillation: Evaluation of sedation safety with midazolam by means of EtCO and IPI algorithm analysis. Int J Cardiol 2013.

15. Pugh PJ, Spurrell P, Kamalvand K, Sulke AN. Sedation by physician with diazepam for DC cardioversion of atrial arrhythmias. Heart 2001; 86:572-573.

16. Mitchell AR, Chalil S, Boodhoo L, Bordoli G, Patel N, Sulke N. Diazepam or midazolam for external DC cardioversion (the DORM Study). Europace 2003; 5:391-395.

17. Staretz LR, Otomo-Corgel J, Lin JI. Effects of intravenous midazolam and diazepam on patient response, percentage of oxygen saturation, and hemodynamic factors during periodontal surgery. J Periodontol 2004; 75:1319-1326.

18. Zakko SF, Seifert HA, Gross JB. A comparison of midazolam and diazepam for conscious sedation during colonoscopy in a prospective double-blind study. Gastrointest Endosc 1999; 49:684-689.

19. Macken E, Gevers AM, Hendrickx A, Rutgeerts P. Midazolam versus diazepam in lipid emulsion as conscious sedation for colonoscopy with or without reversal of sedation with flumazenil. Gastrointest Endosc 1998; 47:57-61.

20. Van Houten JS, Crane SA, Janardan SK, Wells K. A randomized, prospective, double-blind comparison of midazolam (Versed) and emulsified diazepam (Dizac) for opioid-based, conscious sedation in endoscopic procedures. Am J Gastroenterol 1998; 93:170-174.

21. Agelink MW, Majewski TB, Andrich J, Mueck-Weymann M. Short-term effects of intravenous benzodiazepines on autonomic neurocardiac regulation in humans: a comparison between midazolam, diazepam, and lorazepam. Crit Care Med 2002; 30:997-1006.

22. Sanders LD, Davies-Evans J, Rosen M, Robinson JO. Comparison of diazepam with midazolam as i.v. sedation for outpatient gastroscopy. Br J Anaesth 1989; 63:726-731.

23. Friedman G, Gehrke L, Oliveira RP, Becker M. Diazepam or Midazolam for Tracheal Intubation in the ICU? Intensive Care Med 2006; 32[suplemment], S250.

24. Knaus WA, Draper EA, Wagner DP, Zimmerman JE. Apache II: a severity of disease classification system. Crit Care Med 1985; 13:818-829.

25. Henthorn TK, Krejcie TC, Avram MJ. Early drug distribution: a generally neglected aspect of pharmacokinetics of particular relevance to intravenously administered anesthetic agents. Clin Pharmacol Ther 2008; 84:18-22.

26. Olkkola KT, Ahonen J. Midazolam and other benzodiazepines. Handb Exp Pharmacol 2008; 182:335-360.

27. Oldenhof $\mathrm{H}$, de Jong $\mathrm{M}$, Steenhoek A, Janknegt R. Clinical pharmacokinetics of midazolam in intensive care patients, a wide interpatient variability? Clin Pharmacol Ther 1988; 43:263-269.

28. Roberts DJ, Haroon B, Hall RI. Sedation for critically ill or injured adults in the intensive care unit: a shifting paradigm. Drugs 2012; 72:1881-1916.

29. Escobar L, Gai MN, Regueira T, Andresen M. Pharmacokinetic considerations in critically ill patients. Rev Med Chil 2012; 140:780-788.

30. Raza SM, Masters RW, Zsigmond EK. Comparison of the hemodynamic effects of midazolam and diazepam in patients with coronary occlusion. Int J Clin Pharmacol Ther Toxicol 1989; 27:1-6.

31. Ely EW, Truman B, Shintani A, Thomason JW, Wheeler AP, Gordon S, et al. Monitoring sedation status over time in ICU patients: reliability and validity of the Richmond Agitation-Sedation Scale (RASS). JAMA 2003; 289:2983-2991. 